\title{
Thoracic and Lumbar Fractures: Mini-Open Anterior Fusion in 138 Patients
}

\section{Ersin Haciyakupoglu* and Kristian Ebmeier}

Department of Neurosurgery, Heinrich Braun Hospital, Karl-Keil-Strasse Zwickau, Germany

*Corresponding author: Ersin Haciyakupoglu, Department of Neurosurgery, Heinrich Braun Hospital, Karl-Keil-Strasse 35, 08058, Zwickau, Germany, Tel: 004915253169864; E-mail: ersin.haciyakupoglu@hbk-zwickau.de

Rec Date: November 13, 2017; Acc Date: December 01, 2017; Pub Date: December 05, 2017

Copyright: (c) 2017 Haciyakupoglu E, et al. This is an open-access article distributed under the terms of the Creative Commons Attribution License, which permits unrestricted use, distribution, and reproduction in any medium, provided the original author and source are credited.

\begin{abstract}
Background: Several surgical procedures have been recommended for the management of thoracic and lumbar fractures. Nowadays Mini- Open Anterior Fusion is reported to be a safe and effective alternative treatment for various spinal pathologies.

Aim: The aim of this study is to report the outcome of 138 cases who underwent mini open thoraco-lumbar surgery for thoracic and lumbar fractures.

Material and Methods: We performed a non-randomized retrospective analysis of the clinical outcome of 138 patients with 140 fractures who underwent mini open thoraco-lumbotomy surgery, between 2011 and 2016 . Follow up periods were 6th weeks, 3rd and 6th months and also 1 year postoperatively. All the patients were operated with mini open thoraco/lumbotomy system (Syn-Frame). All of our patients with fractures, undervent posterior pedicle screw fixation prior to the anterior fusion just after the posterior fusion or a couple of days later (mean: $4.2 ; 2$ to 7 days), depending on the general condition of patients. Thorax drainage was placed to all thoracotomy patients $(63 \%$ to $87 \%)$.
\end{abstract}

Results: Fractures of 13 cases were due to tumor metastasis, and the rest of them were due to acute fractures, spondylodiscitis. 87 cases had thoracic (T6-T12) and 51 cases had lumbar (L1-L5) fractures.

Discussion: Several methods are being used in order to achieve safe, and minimaly invasive approach in cases with thoracolumbar pathologies. The complication rates of this procedure are similar to endoscopy assisted thoracotomy. Syn-Frame System allows the opportunity to perform even 2-3 levels corpectomy and stabilization through a $5 \mathrm{~cm}$ skin incision. It is possible to insert 4 or more retractors from all angles to form an area just over the level operation level, without dealing with aorta, lung, urethra or heart.

Conclusion: We can estimate that this approach is safe, minimally invasive and effective besides reducing the pain and morbidity of conventional methods.

Keywords: Thoracic; Lumbotomy; Spondylodiscitis; Retroperitoneal organs

\section{Introduction}

Several surgical procedures have been recommended for the management of thoracic and lumbar fractures. Nowadays, minimally invasive methods are reported to be safe and effective alternative treatment for various spinal pathologies [1-7].

Most of the spinal surgeons prefer posterior stabilization [8,9] but it is known that the anterior column is responsible for $80 \%$ of the load in spine [10]. Slosar described the limitations of transpedicular instrumentation [11]. In behalf of this, performing the posterior fixation alone may result with an insufficient stabilization [12]. Zhao et al. operated 26 of 235 posterior fusion patients anteriorly because of late complications (11\%) [13]. Fusion rates are higher and complications due to lack of trabeculation are lower in posteroanterior fusion, in comparison with the posterior fusion alone [10,14].
It is reported that mini open approach is safe and effective for the treatment of spinal fractures besides the advantages of minimum blood loss, less pain and less morbidity [1-5].

Up to our knowledge this case series is the largest one. The aim of the study is to determine whether an anterior mini open surgery improves the outcome and to document the advantages of this approach.

\section{Patients and Methods}

This is a non-randomized retrospective analysis of the clinical outcome of 138 patients with 140 fractures who underwent mini open thoraco-lumbotomy surgery between 2011 and 2016. All of our patients with fractures, underwent posterior pedicle screw fixation prior to the sil anterior fusion just after the posterior fusion or a couple of days later (mean: 4.2, 2 to 7 days), depending on the general condition of patients. 
Citation: Haciyakupoglu E, Ebmeier K (2017) Thoracic and Lumbar Fractures: Mini-Open Anterior Fusion in 138 Patients . J Spine 6: 398. doi:

Postoperative follow up period was $6^{\text {th }}$ weeks, $3^{\text {rd }}$ and $6^{\text {th }}$ months and also 1 year following the surgery. CT scan was performed in every case postoperatively. In cases with metastasis and spondylodiscitis an MRI scan was also performed. Amount of pain medications were evaluated. All patients with burst fractures or tumors/infections causing spinal stenosis were operated with posterior pedicle screw fixation and posterior decompression before anterior fusion operation $(78.2 \%)$.

\section{Surgery}

All of the patients were operated in lateral decubitus position, depending on the pathology, right or left sided. After fluoroscopic vision, approximately $6 \mathrm{~cm}$ skin incision (Figure 1) was performed right above the pathologic vertebrae for mini open surgery.

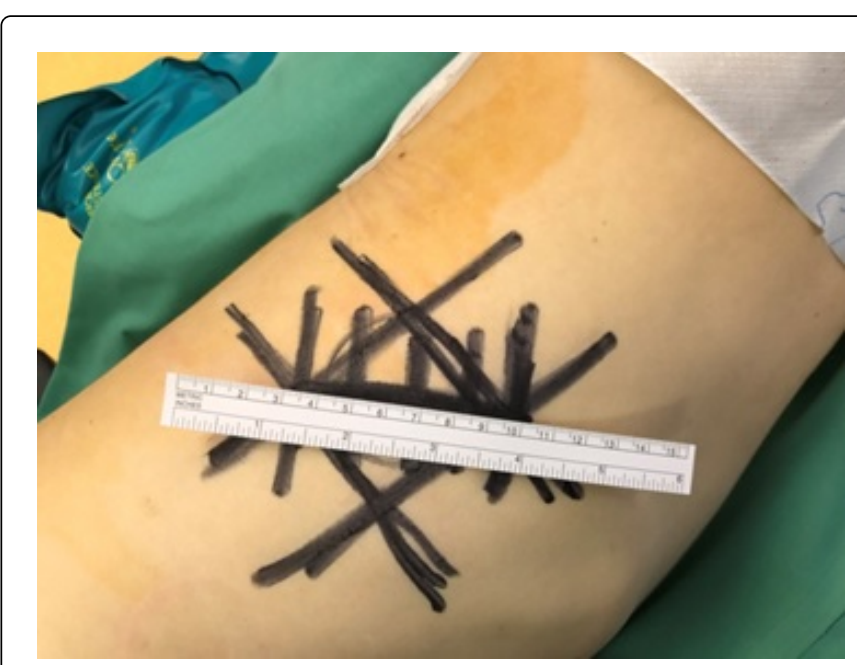

Figure 1: The skin incision (Directly over the vertebra, approximately $5-6 \mathrm{~cm}$ ).

After fixating the holding arms at the operating table, the SynFrame ring was fixed right over the incision (Figure 2). We placed mostly 4 or more retractors at the ring and formed a cone shaped opening over the pathologic vertebra. A second fluoroscopy was applied to verify the exact level.

For thoracotomy, we applied a star formed incision at inner layer of pleura and afterwards we carefully dissected the segmental arteries of that level in order to avoid bleeding (Figure 3). Dissected arteries were bound from two sides with $2 / 0$ monofilament sutures and cut with a scissor.

For lumbotomy procedure, psoas muscle has to be eckardated. This can be done by a simple cut of the muscle or percutaneus opening in between the muscle. In either way a painfull movement of tight may occur postoperatively, but would end in a couple days without any need of an additional imaging. The second important factor in lumbotomy is to avoid a cut at the urethra. Urethra is very fragile and if the surgeon does not realize the anatomy, it could easily be damaged and result with serious problems.

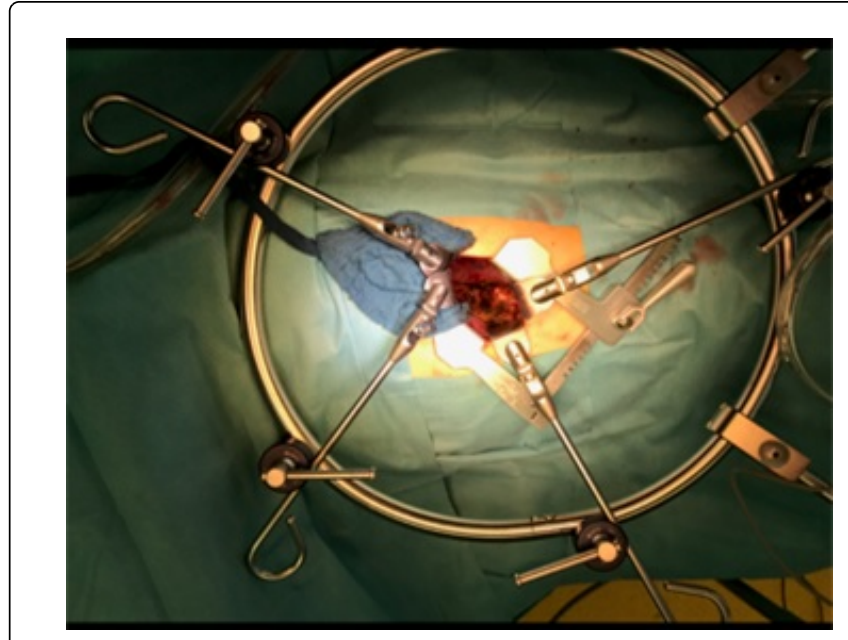

Figure 2: Syn-Frame placed with the retractors to form a conic space directly to the pathologic vertebra.

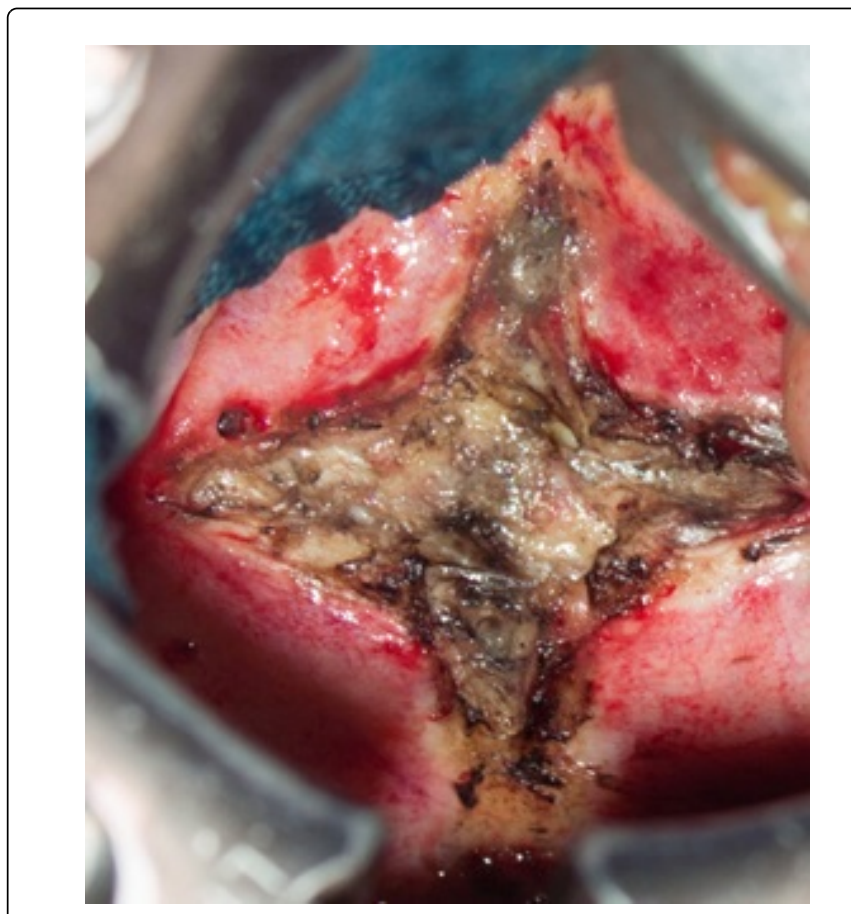

Figure 3: Inner layer of pleura is opened to reach the vertebra anteriorly.

After visualization of pathologic vertebra, we removed the neighboring discs first and applied corpectomy as usual. Afterwards expandable cage filled with allograft bone fragments was placed (Figure 4). 


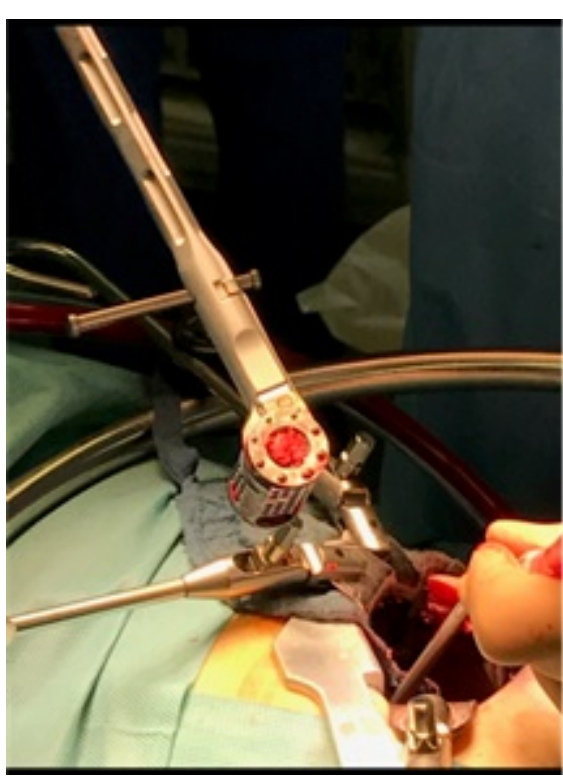

Figure 4: Replacement of distractable cage, filled with bone fragments, instead of the removed vertebra.

If needed, additional screw-plate stabilization anteriorly is done ( $66.6 \%$ of thoracotomy and $23.5 \%$ of lumbotomy patients). Thorax drainage was placed to all thoracotomy patients (n:87), and they stayed for one night at the intermediate care unit.

\section{Results}

The study group consisted of 83 males with amean age of 39.1 years (22-82 years)] and 55 female patients with a mean age of 65.8 years (26-82 years). We applied mini open thoraco/lumbotomy system (SynFrame) to 138 patients with 140 fractures. 13 of them were due to tumor metastasis, and the rest were due to acute fractures, spondylodiscitis.

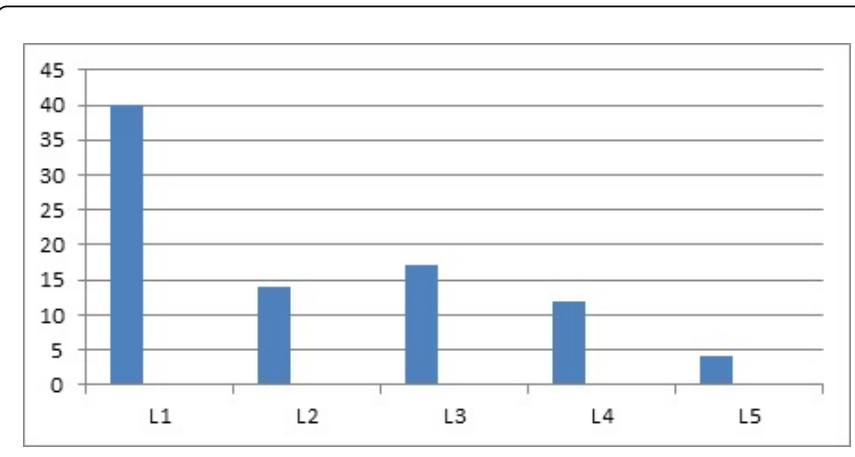

Figure 5: Distribution of lumbar levels.

The spinal metastasis was due to Breast cancer in 4 (T7, T10, T11, L1), Multiple Myeloma in $5(\mathrm{~T} 7, \mathrm{~T} 9, \mathrm{~T} 12(\times 2), \mathrm{L} 3)$, and Urothelial tumor (T10), Renal cell carcinoma (L1/2), Bronchial carcinoma (L2) and Oropharynx carcinoma (L5).
87 patients had thoracic (T6-T12) and 51 patients had lumbar (L1L5) fracture (Figures 5 and 6).

The highest thoracic level was T6, and T12 had the highest operation rate. The most operated segment for lumbar pathologies was L1. 2 patients underwent anterior mini thoraco/lumbotomy for 2 level fractures (L1 and L3, L1 and L4). We used titan cages as the graft material. All patients were sent to a rehabilitation clinic for at least 3 weeks. Post-operative follow-up periods were 6th weeks, 3rd and 6th months and also 1 year after the surgery. CT scans were performed, direct postoperatively, as well as in follow up periods in order to detect a complication and to evaluate the trabeculation. In cases with metastasis and spondylodiscitis an MRI scan was added to evaluate the current situation of tumor/infection. All spondylodiscitis patients were treated at least 3 months with antibiotic $(21 \pm 3$ days I.V, afterwards orally).

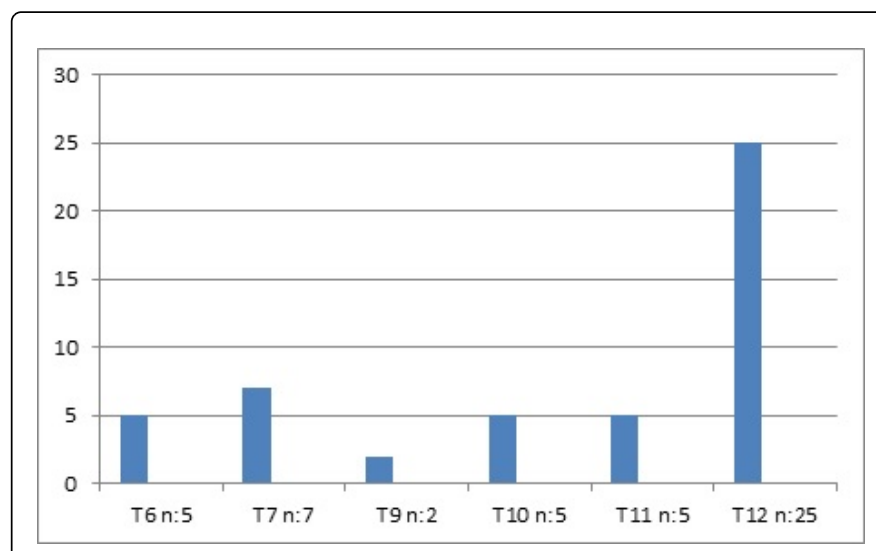

Figure 6: Distribution of thoracic levels.

Additional pain medications were not needed in 87 of the cases. 51 patients $(36.9 \%)$ had increased pain after the second (thoracolumbotomy) operation and additional pain medication was applied, for the other patients we just extended the time of pain therapy for one week after the first operation. Additional neurological deficits were not observed.

In 11 cases we detected iliopsoas muscle weakness due to painful movement of tight (21.5\%), which were also not detectable in neurological examination and the complaints ceased after a couple of days.

Mean operation time was $182.18(135-240) \mathrm{min}$ in 2011, 151.04 (90-210) $\mathrm{min}$ in $2012,138.68$ (95-200) $\mathrm{min}$ in 2013, 135.38 (95-255) $\mathrm{min}$ in $2014,135.79(85-215) \mathrm{min}$ in 2015 and 140,41 (95-200) $\mathrm{min}$ in 2016. Mean operation time for 6 years is $147.24 \mathrm{~min}$. Operation time can be less than $90 \mathrm{~min}$ for a thin and healthy patient.

Mean blood loss during the operation was $589.79 \mathrm{ml}$. Just 4 patients needed blood transfusion because of excessive bleeding over $1500 \mathrm{ml}$. One them had a double level corpectomy, and the other three patients were multi morbid and over 65 years of age.

Total complications rate was $8.7 \%$. We did not detect any major complications like vessel injuries, urethral puncture or dura tear, no deep vein thrombosis.

Our major complication was intra operative suspect of urethral puncture in one case. The urologists did not detect any puncture at the 
Citation: Haciyakupoglu E, Ebmeier K (2017) Thoracic and Lumbar Fractures: Mini-Open Anterior Fusion in 138 Patients . J Spine 6: 398. doi:

Page 4 of 5

pre-operative period and an urethral catheter was placed immediately. Postoperative diagnostic scans also did not reveal a rupture.

Wound healing problems was seen in 4 cases and local wound revisions were performed.

Also we detected pleural effusion in 4 cases after removal of thorax drain. None of them had to be reoperated and were followed up with chest-x-ray scans.

In three of our patients, all over 70 years of age, we had to perform re-stabilization because of screw looseness due to new trauma. In two of these cases we had to replace the corpectomy cage, but all of them had to be restabilised dorsally.

\section{Illustrative Case}

A 26-year-old male patient, jumped down from the $4^{\text {th }}$ floor to commit suicide. Initial neurological examination was not clear; he was intubated immediately and was brought to Heinrich-Braun-Clinic emergency unit. The polytrauma CT scan showed L1 and L3 burst fractures causing spinal stenosis. No additional vital problems were detected. We immediately performed a posterior fusion and decompression of the spinal canal in order to avoid any neurologic disturbance which was performed immediately (Figures 7 and 8).

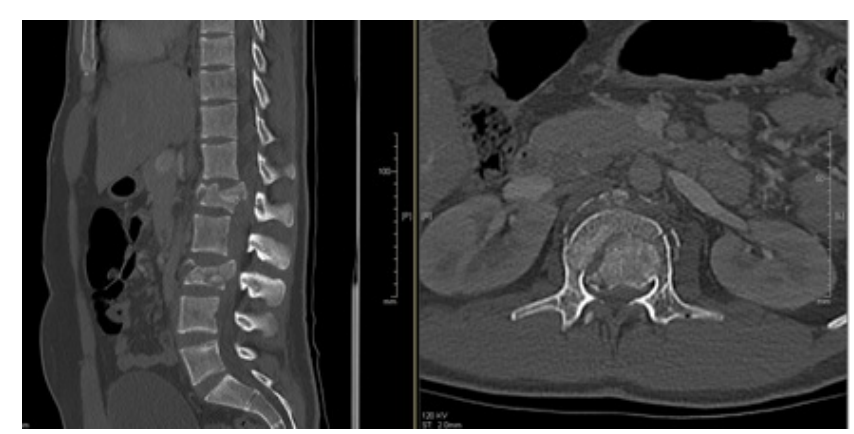

Figure 7: Preoperative sagittal and axial CT scans, showing the burst fractures of L1 and L3.

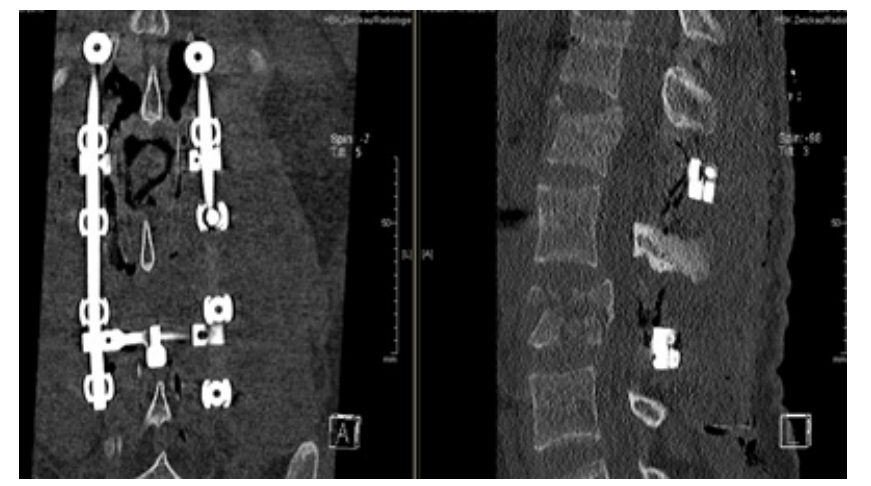

Figure 8: Post-operative sagittal and coronar CT scans after posterior fusion and decompression.

Neurological deficits were not detected post-operatively. We applied anterior mini open thoracoto/lumbotomy and corpectomy procedure,
5 days after the initial operation over two opennings (Figure 9). The patient was mobilized the day after and no complications occurred. The patient is still on follow up without any complications (Figure 10).

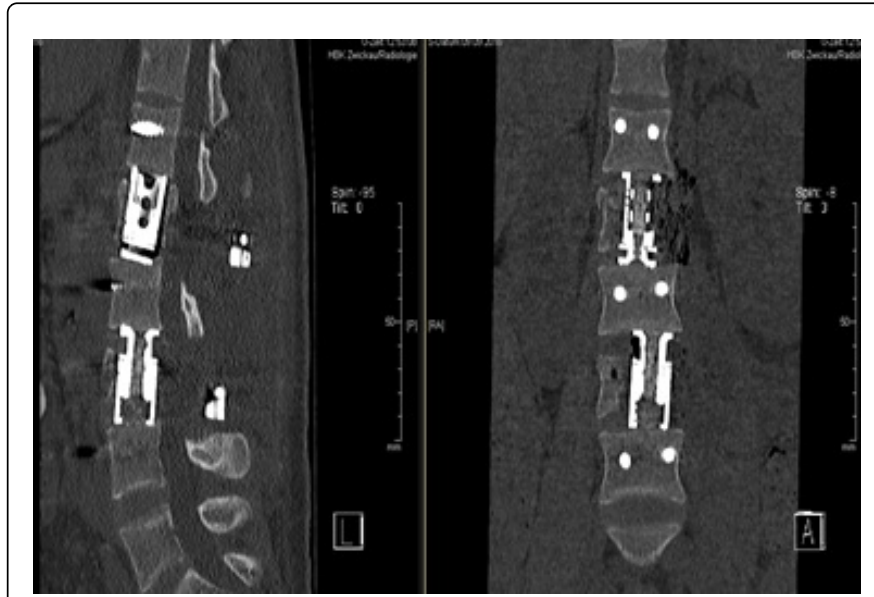

Figure 9: Post-operative sagittal and coronar CT scans after mini open anterior corpectomy/fusion.

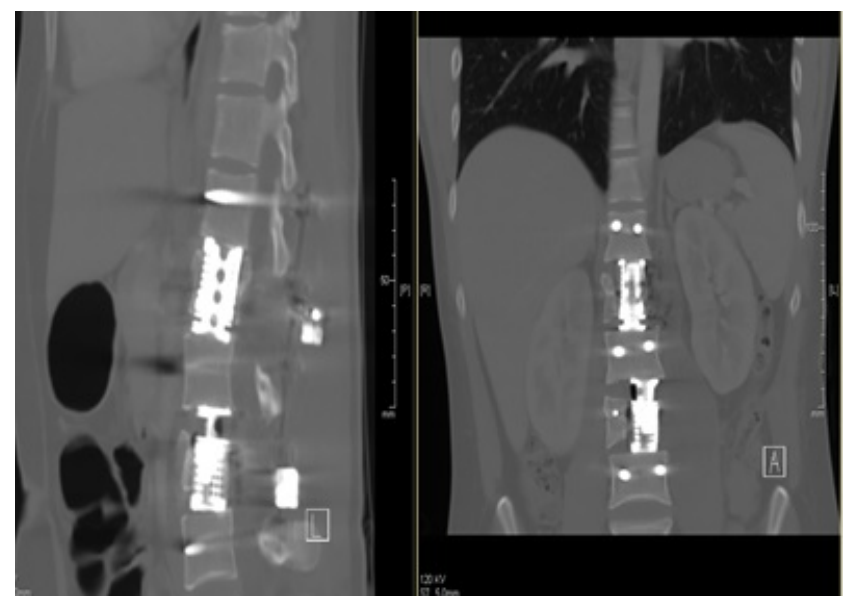

Figure 10: A 6 months follow up, sagittal and coronar CT scans of the patient.

\section{Discussion}

Anterior fusion can be applied transperitoneally or transsternally, endoscopy assisted, classic thoraco/lumbotomy or mini-open approach $[1-6,13,15]$ The way to perform anterior surgery mostly depends on the experience of the surgeon.

Anterior lumbar interbody fusion is first described by Ito and Cerpenter to treat spondylolisthesis and tuberculosis [16,17]. Reaching the spine anteriorly and retro- peritoneally, was then described by Ley et al. [18]. Vertebral body replacement could be done with autologous bone or distractible titanium cages. Vieweg et al. presented 30 cases treated with distractible titanium cages, filled with autologous bone fragments and documented bony fusion in 27 of them, mean follow up period was 14 months [19]. Treating the pathology from anterior way, without opening the peritoneum with less post- operative bowel 
problems was one of the biggest advantages of the approach, however, vessel injuries, urethral injuries, retrograde ejaculation, psoas and abdominal muscle weakness and large dissection are the weaknesses of this approach $[15,20,21]$.

Many authors used different methods to make this approach safer and easier. Endoscopic surgery is one of these methods for the thoracolumbar spine $[2,4,22]$. Verheyden et al. performed endoscope assisted thoracolumbar anterior fusion in prone position which allowed them to perform combined posterior and anterior surgery [23]. They did not have major complications, but the learning curve of endoscopic surgery is longer and it costs more than a conventional method [23,24]. Mini open surgery is also cost effective in comparison to classic thoracotomy, less morbid and safe. Sulaiman et al. published their research comparing the cost effectiveness of both methods [6] In anterior mini open surgery, surgeon deals with the familiar anatomy of spine without the additional risks of open thoraco/lumbotomy [6]. Peyer et al. operated 37 patients with mini open approaches and documented the advantages [7]. The complication rate of this procedure is lower than the classic one and similar to endoscopy assisted thoracotomy.

Syn-Frame System gives the opportunity to perform even 2-3 levels corpectomy and stabilization from approximately $5 \mathrm{~cm}$ skin incision. It is possible to insert 4 or more retractors from all angles to form an area just over the operation level, without dealing with aorta, lung, urethra or heart $[1,4,8]$.

We apply mini thoraco/lumbotomy procedure in our clinic for the last 6 years without the help of other departments. Experience is one of the key points to perform such operations.

\section{Conclusion}

In comparison to the classic thoraco-lumbotomy, mini open surgery is a comfortable method providing easy and fast reach to the pathology. Also, classical thoraco- lumbotomy is known to be a painful procedure, whereas mini open lumbo-thoracotomy has better pain outcome $[1,4,8,13]$.

We can suggest that mini open lumbo-thoracotomy is a safe and effective approach in the treatment of spinal fractures besides the advantages of minimum blood loss, less pain and less morbidity.

\section{References}

1. Lall RR, Smith ZA, Wong AP, Miller D, Fessler RG (2012) Minimally invasive thoracic corpectomy: Surgical strategiesfor malignancy, trauma and complex spinal pathologies. Minim Invasive surg 2012: 213791.

2. Khoo LT, Beisse R, Potulski M (2002) Thoracoscopic-assisted treatment of thoracic and lumbar fractures: A series of 371 consecutive cases Neurosurgery 51: S104-117.

3. Baaj AA, Dakwar E, Le TV, Smith DA, Ramos E, et al. (2012) Complications of the mini-open approach to the thoracolumbar spine. J Clin Neurosci 19: 1265-1267.

4. Kossmann T, Jacobi D, Trentz O (2001) The use of a retractor system (SynFrame) for open, minimal invasive reconstruction of the anterior column of the thoracic and lumbar spine. Eur Spine J 10: 396-402.
5. Khan SN, Cha T, Hoskins JA, Pelton M, Singh K (2012) Minimally invasive thoracolumbar corpectomy and reconstruction. Orthopedics 35: 74-79.

6. Sulaiman OAR, Garces J, Mathkour M, Scullen T, Jones RB, et al. (2017) Mini-open thoracolumbar corpectomy:perioperative outcomes and hospital cost analysis compared with open corpectomy. World Neurosurgery 99: 295-301.

7. Payer M, Sottas C (2008) Mini-open anterior approach for corpectomy in the thoracolumbar spine. World Neurosurgery 69: 25-31.

8. Strambough JL (1997) Posterior instrumentation for thoracolumbar trauma. Clin Ortoph Relat Res 335: 73-88.

9. Müller U, Berlemann U, Sledge J, Schwarzenbach O (1999) Treatment of thoracolumbar burst fractures without neurologic deficit by indirect reduction and posterior instrumentation: bisegmental stabilization with monosegmental fusion. Eur Spine J 8: 284-289.

10. Duffield RC, Carson WL, Chen LY, Voth B (1993) Longitudinal element size effect on load sharing, internal loads, and fatigue life of tri-level spinal implant constructs. Spine 18: 1695-1703.

11. Slosar PJ Jr, Patwardhan AG, Lorenz M, Havey R, Sartori M (1995) Instability of the lumbar burst fracture and limitations of transpedicular instrumentation. Spine 20: 1452-1461.

12. Knop C, Blauth M, Bühren V, Max PM, Kinzl L, et al. (2000) Operative Behandlung von Verletzungen des thorakolumbalen Übergangs. Teil 2: Operationen und röntgenologische Befunde. Unfallchirurg 103: 1032-1047.

13. Zhao,J, Schaser KD, Zhang F (2010) Revision surgery for posterior stabilized thoracolumbar fracture using mini-open anterior approach and expandable cage. Ort Surgery 2: 100-105.

14. Goel VK, Kim YE, Lim TH, Weinstein JN (1988) An analytical investigation of the mechanics of spinal instrumentation. Spine 13: 1003-1011.

15. Saraph V, Lerch C, Walochnik N, Bach CM, Krismer M, et al. (2004) Comparison of conventional versus minimally invasive extraperitoneal approach for anterior lumbar interbody fusion. Eur Spine J 13: 425-431.

16. Ito H, Tsuchiya J, Asami G (1934) A new radical operation for Pott's disease. J Bone Surg 16B: 499-515.

17. Capner N (1932) Spondylolisthesis. Br J Surg 19: 374-386.

18. Ley EB, Thurston WD (1954) Retroperitoneal approach to lumbar disc. Rocky Mt Med J 51: 121-123.

19. Vieweg U, Sölch O, Kalff R (2003) Vertebral body replacement system syntex in unstable burst fractures of the thoracic and lumbar spine- $\mathrm{A}$ retrospective study with 30 patients. Zentralblatt Neurochirurgie 64: 58-64.

20. Baker JK, Reardon PR, Reardon MJ, Heggeness MH (1993) Vascular injury in anterior lumbar surgery. Spine 18: 2227-2230.

21. Rajaraman V, Vingan R, Roth P, Heary RF, Conklin L, et al. (1999) Visceral and vascular complications resulting from anterior lumbar interbody fusion. J Neurosurg 91: 60-64.

22. Verheyen AP, Katscher S, Gonschorek H, Lill H, Josten C (2002) Endoskopisch assistierte Rekonstruktion der thorakolumbalen Wirbelsäule in Bauchlage. Der Unfallchirurg, 105: 873-880.

23. Foley KT, Holly LT, Schwernder JD (2003) Minimally invasive lumbar fusion. Spine 28: 26-35.

24. Mayer HM (1997) A new microsurgical technique for minimally invasive anterior lumbar interbody fusion. Spine 22: 691-699. 